\title{
Desarrollo de cultivos y alimentos por técnicas de biotecnología moderna en Centroamérica
}

\author{
Development of food crops by modern \\ biotechnology techniques in Central America
}

Giovanni Garro Monge'

Fecha de recepción: 20 de enero del 2012

Fecha de aprobación: 19 de marzo del 2012

Garro, G. Desarrollo de cultivos y alimentos por técnicas de biotecnología moderna en

Centroamérica. Tecnología en Marcha. Vol. 25, № 5.

Pág 40-54. 


\section{Palabras clave}

Biotecnología, Cultivos Genéticamente Modificados (CGM), OGM, Centroamérica, inocuidad alimentaria, alimentos funcionales.

\section{Resumen}

En la última década, la adopción de Cultivos Genéticamente Modificados (CGM) se ha incrementado de forma escalonada a nivel mundial. El área sembrada con cultivos biotecnológicos llegó a un total de 148 millones de hectáreas en 2010, aumentando también el número de agricultores que decidieron producir este tipo de cultivos.

A nivel regional, se producen respuestas diversas de los órganos gubernamentales mediante reglamentos y normativas acordes con la realidad local. En Centroamérica, los países con mayor participación en el desarrollo y cultivo de alimentos utilizando técnicas de biotecnología moderna son Guatemala (papaya), Honduras (frijol y maíz) y Costa Rica (algodón, soya y piña). En el 20l0, los dos últimos países estaban entre los 29 países con mayor siembra de CGM a nivel mundial. Algunos países de la región han implementado estructuras gubernamentales para la regulación por medio de comisiones técnicas de Bioseguridad.

Las características más importantes en términos del comercio siguen siendo aquellas que confieren tolerancia a herbicidas o resistencia a plagas. Sin embargo, se nota la incursión de nuevos productos que contienen modificaciones en su contenido y que se vislumbran como una alternativa con buenas perspectivas en la región.

Estas experiencias de cultivo y regulación en Bioseguridad a escala regional podrían suponer un desarrollo acertado y progresivo de la biotecnología agrícola y alimentaria en un futuro cercano.

\section{Key words}

Biotechnology, Genetically Modified Crops (GMC), Central America, GMO, food safety and functional foods.

\begin{abstract}
In the last decade, the adoption of Genetically Modified Crops (GMC) has increased in stages worldwide. The worldwide total area planted with biotech crops reached 148 million hectares by 2010 , also increasing the number of farmers around the world who decided to produce crops with this technology.
\end{abstract}

At the regional level there are different responses of government agencies by generating rules and regulations according to the reality of these countries. In Central America, countries with greater participation in the development and cultivation of food biotechnology techniques are Guatemala (papaya), Honduras (beans and maize) and Costa Rica (cotton, soybean and pineapple), placing the latter two in the 29 countries with more GMO planting crops worldwide in 2010 . Some of the countries of the region have implemented governance structures for the regulation through technical committees on Biosafety.

The most important characteristics in terms of trade continue to be those that confer herbicide tolerance or pest resistance. But notice the incursion of new products that contain changes in their content, which are emerging as an alternative with great perspectives in the region.

These experiences of culture and Biosafety regulation at the regional level could be a successful and progressive development of agricultural and food biotechnology in the near future. 


\section{Introducción}

La aplicación de la biotecnología en la producción de alimentos existe desde hace miles de años y es una de las técnicas más antiguas de las que se tiene conocimiento. El uso de hongos y bacterias para la producción de alimentos como pan, vino y quesos es uno de los ejemplos más claros en los que e han usado organismos vivos, o parte de ellos, para generar bienes o servicios desde épocas antiguas.

La biotecnología ha evolucionado mucho, convirtiéndose en uno de los campos de la ciencia más importantes y con muchas áreas aún por explotar, debido a los beneficios que presenta para la sociedad y el medio ambiente.

Además de mejorar productos para bajar costos o mejorar procesos de producción, la biotecnología contribuye a dar respuesta a la incógnita de la alimentación mundial. Las expectativas de suplir de alimentos a la población mundial son cada vez más ambiciosas en términos de cantidad y calidad. Así, la biotecnología ofrece alternativas inocuas, ambientalmente sostenibles y de producción escalonada.

\section{Definición}

Los alimentos mejorados por biotecnología moderna, conocidos mundialmente como GMO (Genetically Modified Organisms) u Organismos Genéticamente Modificados (OGM) en español, representan el avance de mayor impacto comercial en los últimos 20 años de la agricultura moderna. Estos desarrollos se refieren al uso de técnicas de ingeniería genética que permiten insertar de forma dirigida secuencias génicas en los genomas de los cultivos o alimentos, con el fin de que las mismas se incorporen y expresen de forma adecuada como un nuevo rasgo o característica propia de la planta.

La implementación de estas técnicas modernas ha logrado varios objetivos, entre ellos mejorar e incrementar la velocidad de los procesos productivos, obtener alimentos en un menor periodo de tiempo, mejorar las características organolépticas y de calidad nutricional de los productos, así como la inserción de genes de resistencia en herbicidas y plaguicidas. Por otro lado, se ha logrado también resistencia a condiciones ambientales adversas como sequía, salinidad y presencia de metales pesados.
Si bien estas técnicas de la biotecnología han permitido desarrollar cultivos y alimentos de forma más dirigida en comparación con las técnicas convencionales de mejora genética, se deben ubicar de forma alterna y complementaria a las técnicas convencionales, en las cuales se basa el desarrollo actual del 98\% de los alimentos vegetales y animales que se consumen (Garro, 2004).

\section{Inocuidad de los alimentos}

Los alimentos mejorados mediante técnicas de biotecnología moderna han causado mucha polémica desde su aparición, por consideraciones generales sobre su inocuidad. Diversos grupos ambientalistas han generado gran cantidad de información que rechaza el uso de estas técnicas, apoyándose en argumentos fáciles de entender en términos comerciales e ideológicos pero difíciles en términos científicos (Vidal, 2004).

Absolutamente todos los productos que se obtienen por técnicas de biotecnología moderna deben aprobar una serie de estudios (de laboratorio y campo) antes de ser liberados al mercado; estudios a los cuales no son sometidos los alimentos producidos en forma convencional u orgánica (Konig et al., 2004).

Este minucioso análisis de los cultivos OGM ha generado gran cantidad de información, que más bien podría ayudar a prevenir muchos de los problemas sanitarios que en el pasado han ocasionado alimentos producidos por otras técnicas como la orgánica y la convencional (Garro, 2004).

Estas pruebas son de larga duración y las realizan de forma estandarizada instituciones gubernamentales y privadas a escala mundial (FDA, USDA, FAO, UNESCO, OMS). En ellas, en términos de inocuidad, el análisis se centra en estudiar básicamente si se han introducido alérgenos en la planta o bien si se han modificado los niveles de alérgenos preexistentes en el cultivo.

Para esto se analizan características que comparten los alérgenos, como la resistencia a la digestión, la prevalencia en el alimento y la similitud con otras proteínas alergénicas; mediante estudios bioinformáticos que permiten comparar la secuencia del nuevo gen con la de los alérgenos conocidos (ArgenBio, 20II) 
Todos los cultivos transgénicos que hoy se consumen han sido analizados desde el punto de vista de su seguridad ambiental e inocuidad alimentaria, incluyendo en esta su potencial alergénico.

Gracias a técnicas como la ingeniería genética se ha logrado eliminar sustancias nocivas en determinados cultivos de interés, como, por ejemplo, aquellas relacionadas con la alergenicidad del maní. Utilizando la tecnología del ARN de interferencia, científicos estadounidenses consiguieron silenciar el gen que produce una de las proteínas más alergénicas del maní. Técnicas como el ELISA demostraron, en algunas líneas, hasta la ausencia total de este alérgeno, y a su vez se comprobó que el resto de las características de las plantas no resultaron alteradas (ArgenBio, 20l I).

Asimismo, se ha trabajado en soja para disminuir su potencial alergénico. La soja es uno de los alimentos que puede producir alergia en ciertas personas y la mitad de los casos se debe específicamente a una proteína, denominada P34. Recientemente, un grupo de investigadores demostró que es posible silenciar la expresión del gen correspondiente sin alterar la maduración ni la composición de las semillas (ArgenBio, 2007).

Debido a los análisis acertados y realizados en el tiempo debido, ninguno de los productos en que se usaron técnicas de biotecnología moderna liberados al mercado ha presentado riesgo para la salud de las personas, demostrando así que son tan seguros como los derivados de sus pares convencionales.

\section{Principales características utilizadas}

Los alimentos mejorados por la biotecnología moderna han abarcado el mercado con una amplia gama de características de interés. Entre ellas, podemos mencionar que se ha logrado modificar desde caracteres de interés agronómico (primera generación) y mejoras en el procesamiento de alimentos (segunda generación) hasta características relacionadas con la nutrición o modificación en su composición (tercera generación). Entre las características agronómicas más conocidas están los genes que confieren resistencia a plagas y tolerancia a herbicidas, los cuales contribuyen al rendimiento de los cultivos y disminuyen la contaminación del medio ambiente.
En estudios recientes se ha evaluado el impacto real de la adopción de cultivos biotecnológicos con resistencia a insectos, los cuales han concluido que esta tecnología genera impactos ambientales menores que los cultivos tradicionales y aumenta los rendimientos totales de producción.

Traxler et al. (2003) realizaron estudios de impacto económico en varias regiones de México y Estados Unidos sobre la introducción de cultivos OGM y el uso de pesticidas utilizando la tecnología Bt (Bacillus thurigensis), que le provee a las plantas genes de resistencia a insectos. Así, por ejemplo, en plantaciones de algodón atacadas por el gusano rosado del algodón en la localidad de Comarca Lagunera (Coahuila, México) se logró reducir el uso de pesticidas desde 12 aplicaciones que se realizaban en el pasado (1996), con el uso de tecnologías convencionales, hasta solo dos en el 200 I en los lugares donde se usó la tecnología Bt.

Esto representó un ahorro cercano al $80 \%$ en los gastos totales en comparación con las técnicas convencionales

Por otra parte, también se han desarrollado estrategias de resistencia a varios tipos de herbicidas, aunque la mayor parte de las semillas que hoy se comercializan son resistentes al glifosato, un herbicida postemergente de amplio espectro y de baja persistencia en el medio ambiente. A nivel mundial, mediante la ingeniería genética, se han creado especies de algodón, soja y maíz capaces de tolerar este herbicida, compuesto que actúa sobre las rutas de síntesis de los aminoácidos.

El glifosato es un inhibidor competitivo de la enzima 5-enolpiruvilshikimato-3-fosfato sintasa, que participa de la síntesis de aminoácidos aromáticos, los que son esenciales para la síntesis de numerosas proteínas. La enzima se encuentra en plantas y microorganismos, pero no en los animales. La resistencia se obtiene introduciendo en la planta un gen ligeramente diferente obtenido de la bacteria A. tumefaciens, el cual codifica una versión de esta enzima insensible al herbicida (Garro, 2010).

Uno de los nombres comerciales del glifosato es "Roundup", por eso, quienes desarrollaron esta tecnología denominaron a los cultivos tolerantes al glifosato con el nombre de "Roundup Ready" - RR (ArgenBio, 2007). Específicamente, en el 2005, la empresa Monsanto anunció la generación 
de tecnología del algodón, denominada algodón "Roundup Ready Flex", la cual se caracteriza por proporcionar una franja de utilización más amplia para los herbicidas "Roundup" durante toda la temporada de cultivo, prestando más flexibilidad y comodidad a los agricultores.

En el caso de la soja, en 1996 se inscribieron en el Registro Nacional de Propiedad de Cultivares las primeras variedades de soja tolerante al glifosato de la empresa Nidera y ya en la campaña 1997/1998 se sembraron I 750000 hectáreas (ArgenBio, 2007). Actualmente, existen varias empresas semilleras que ofrecen al mercado un gran número de variedades de soja con esta característica.

Asimismo, la empresa Bayer CropScience ha creado una especie resistente a herbicidas y obtuvo la autorización definitiva de su tecnología, conocida como Liberty Link, que permite que las plantas sean tolerantes al glufosinato de amonio, favoreciendo así un control eficaz y amplio de las malas hierbas (Bayer CropScience, 20 I I)

De la misma manera se han desarrollado especies de maíz tolerantes al glifosato, aprobadas para su siembra comercial en 2004, y desde entonces su adopción aumenta en forma sostenida, alcanzando en la última campaña 217000 hectáreas (casi el 10\% del maíz transgénico) (ArgenBio, 2007). Los últimos datos señalan que en la campaña 2006/2007 más del 70\% del algodón transgénico sembrado en Argentina fue tolerante al glifosato (ArgenBio, 2007).

Además de la resistencia a herbicidas e insectos, se han introducido características organolépticas que mejoran la calidad del proceso o manejo postcosecha (Pantanelli, 2007). Entre ellas destacan la maduración retardada (tomate, chile) y la eliminación del pardeamiento a través de la modificación de las rutas enzimáticas en cultivos como los de papas, manzanas, peras y bananos. Así por ejemplo, en Argentina, investigadores del INGEBI-CONICET obtuvieron una variedad de papa con un alto grado de inhibición del pardeamiento que actualmente continúa en estudio (ArgenBio, 2007).

En cuanto a los factores de nutrición que se han modificado, se pueden mencionar la composición o el incremento de alguno de sus componentes y el aumento de betacaroteno y hierro en cereales.

La compañía Monsanto ha producido semillas de rape y mostaza ricas en betacaroteno y más recien- temente los científicos de la Fundación Rockefeller produjeron una variedad de arroz, llamada arroz dorado (Golden rice), que ha sido modificada genéticamente para producir betacaroteno, lo cual ha sido considerado por muchos una importante estrategia para controlar la deficiencia de vitamina A, debido a que el arroz es una de las bases dietéticas de las poblaciones que presentaron mayores deficiencias de la misma, con lo cual se podría reducir este problema, aunque nunca resolver completamente (Garro, 20।0).

Una de las características más nuevas y que aún requiere de estudios ulteriores son los productos farmacológicos en alimentos, lo que se conoce como vacunas orales o vacunas comestibles, y la producción de proteínas humanas en alimentos.

Las prácticas genéticamente modificadas han demostrado una gran capacidad para ser máquinas para producir anticuerpos, los cuales son utilizados en el diagnóstico y tratamiento de varias enfermedades. Existen desarrollos en alfalfa, maíz, arroz, tabaco, banano y papa como fábricas biológicas que producen fármacos, vacunas y plásticos.

En 1995 se iniciaron experimentos con papas genéticamente modificadas para producir la proteína que recubre al virus de la hepatitis $\mathrm{B}$, lográndose que ratas alimentadas con estas papas presentaran una respuesta inmune similar a la que causaría el virus entero (Bioplanet, 200 I).

Asimismo, en Estados Unidos se ha modificado genéticamente una papa que lleva una vacuna contra el cólera, que es semejante en estructura y propiedades a la enterotoxina de E. coli. En los experimentos se observó que comer el tubérculo transgénico puede inocular al individuo contra esta enfermedad; según el equipo de la Universidad Loma Linda de California, en sus pruebas con ratones estos produjeron anticuerpos contra el cólera, aún estando cocinada (Garro, 20I0).

En general, como se muestra en el cuadro I, se han logrado papas, tomates y otras plantas capaces de producir los antígenos del virus Norwalk (causante de diarrea), el virus del sida (HIV-I), la bacteria del cólera (Vibrio cholerae) y el virus de la rabia (Bioplanet, 200 I; Brown, 1997).

En la actualidad, esta estrategia de producción de vacunas abarca una amplia gama de patologías y péptidos inmunógenos: rabia (proteína G), CMV 
(glicoproteína B), hepatitis B (HBsAg), Pseudomonas aeruginosa, Staphylococcus aureus, MEV, malaria, rotavirus e incluso enfermedades autoinmunes como la diabetes (GAD 65 y 67) (Garro, 2010).

Las vacunas comestibles ofrecen muchas ventajas sobre las inyecciones, tal como se muestra en el cuadro 2, ya que las plantas se pueden cultivar en la localidad y de manera económica, utilizando para ello los cultivos tradicionales de una región.

Además, las vacunas comestibles solucionan los problemas del transporte y la conservación, ya que ambos se llevarían de manera normal como se hace con los cultivos, son de alta calidad y producen menos contaminación. Además, su administración puede ser más fácil y más barata, pues por ser relativamente estables, se simplifica la distribución de materiales inmunológicamente activos.

\section{Alimentos funcionales}

Son muchos los productos modificados que se pueden encontrar actualmente en el mercado o en proceso de comercialización. Uno de los más interesantes es el arroz dorado o "golden rice", enriquecido con betacaroteno, un precursor de la vitamina A, desarrollado por el grupo dirigido por el Dr. Ingo Potrykus, un científico suizo de gran renombre mun-

\section{Cuadro I. Principales vacunas humanas o animales expresadas por plantas transgénicas}

\begin{tabular}{|l|c|l|}
\hline \multicolumn{1}{|c|}{ Proteína } & Planta hospedera & \multicolumn{1}{c|}{ Comentario } \\
\hline Proteína de hepatitis B & Tabaco & $\begin{array}{l}\text { Primera vacuna expresada en plantas, tercera } \\
\text { planta en llegar a la fase de ensayos clínicos. }\end{array}$ \\
\hline Glicoproteína del virus de la rabia & Tomate & $\begin{array}{l}\text { Primer ejemplo de una vacuna comestible } \\
\text { expresada en tejidos vegetales comestibles. }\end{array}$ \\
\hline Enterotoxina E. coli & Tabaco, Papa & $\begin{array}{l}\text { Primera vacuna oral en llegar a la fase de ensayos } \\
\text { clínicos }\end{array}$ \\
\hline $\begin{array}{l}\text { Proteína de la cápside del virus Norwalk } \\
\text { Antígeno de la diabetes }\end{array}$ & Papa & $\begin{array}{l}\text { Segunda vacuna oral en llegar a la fase de } \\
\text { ensayos clínicos. }\end{array}$ \\
\hline $\begin{array}{l}\text { Subunidad B de la toxina del cólera } \\
\text { Subunidades B y A2 de la toxina del cólera, } \\
\text { rotavirus y enterotoxinas y fusiones } \\
\text { enterotoxigénicas del antígeno fimbrial de E. coli. }\end{array}$ & Tabaco, Papa & $\begin{array}{l}\text { Primera vacuna oral derivada de una enfermedad } \\
\text { autoinmune. }\end{array}$ \\
\hline \begin{tabular}{l} 
Virus transmisible de la gastroenteritis porcina \\
\hline
\end{tabular} & Tabaco, Papa & Primera vacuna oral expresada en cloroplastos. \\
\hline
\end{tabular}

Fuente: Ma et al. 2003.

Cuadro 2. Cuadro comparativo de sistemas de producción de vacunas recombinantes. Fuente: Ma et al. 2003.

\begin{tabular}{|c|c|c|c|c|c|c|c|}
\hline Sistema & $\begin{array}{l}\text { Costo } \\
\text { Total }\end{array}$ & $\begin{array}{l}\text { Tiempo de } \\
\text { producción }\end{array}$ & $\begin{array}{l}\text { Capacidad de } \\
\text { escalamiento }\end{array}$ & $\begin{array}{l}\text { Calidad de } \\
\text { producción }\end{array}$ & Glicosilación & $\begin{array}{c}\text { Riesgos de } \\
\text { contaminación }\end{array}$ & $\begin{array}{l}\text { Costo de } \\
\text { almacenaje }\end{array}$ \\
\hline $\begin{array}{l}\text { Bacterias } \\
\text { Levaduras } \\
\text { Cultivo células } \\
\text { animales } \\
\text { Animales } \\
\text { Transgénicos } \\
\text { Cultivo de } \\
\text { células vegetales } \\
\text { Plantas } \\
\text { Transgénicas }\end{array}$ & $\begin{array}{l}\text { Bajo } \\
\text { Medio } \\
\text { Alto } \\
\text { Alto } \\
\text { Medio } \\
\text { Muy } \\
\text { Bajo }\end{array}$ & $\begin{array}{l}\text { Corto } \\
\text { Medio } \\
\text { Largo } \\
\text { Muy Largo } \\
\text { Medio } \\
\text { largo }\end{array}$ & $\begin{array}{l}\text { Alta } \\
\text { Alta } \\
\text { Muy baja } \\
\text { Baja } \\
\text { Media } \\
\text { Muy alta }\end{array}$ & $\begin{array}{l}\text { Baja } \\
\text { Media } \\
\text { Muy alta } \\
\text { Muy alta } \\
\text { Alta } \\
\text { Alta }\end{array}$ & $\begin{array}{l}\text { Ninguna } \\
\text { Incorrecta } \\
\text { Correcta } \\
\text { Correcta } \\
\text { Diferencias } \\
\text { menores } \\
\text { Diferencias } \\
\text { menores }\end{array}$ & $\begin{array}{l}\text { Endotoxinas } \\
\text { Bajo riesgo } \\
\text { Virus, priones y } \\
\text { ADN congénito } \\
\text { Virus, priones y } \\
\text { ADN congénito } \\
\text { Bajo riesgo } \\
\text { Bajo riesgo }\end{array}$ & $\begin{array}{l}\text { Moderado } \\
\text { Moderado } \\
\text { Alto } \\
\text { Alto } \\
\text { Moderado } \\
\text { Bajo }\end{array}$ \\
\hline
\end{tabular}


dial. Este arroz busca ser una respuesta muy eficaz en el combate de la ceguera infantil en muchos países con altos índices de pobreza y gran dependencia de este cultivo como su dieta básica.

Además, la vitamina que brindará este arroz pretende evitar lo que provoca su carencia, como la ceguera, exacerbamiento de la diarrea, afecciones respiratorias y enfermedades infantiles como el sarampión en países de África, Asia y América Latina (Garro \& Lam, 2009).

También se ha logrado producir una soya con alto contenido de aceites con ácidos grasos insaturados como el oléico y el esteárico, que suelen ser oxidativamente estables, tienen buenas características de sabor y efectos positivos sobre la salud, en comparación con los aceites ricos en poliinsaturados (linoléico y linolénico) que tienen sabor pobre y baja estabilidad (Garro \& Lam, 2009).

Entre los casos más interesantes se encuentran los productos usados como edulcorantes, que son sumamente importantes en el mercado. Este es un ejemplo de la mejora de alimentos (tomates y lechugas) que contienen genes de taumatina, extraída de Thaumatococcus danielli, o de monelina, proveniente de Dioscoreophyllum cumminsii, que poseen hasta 1000 veces más poder edulcorante que la sacarosa.

Del mismo modo se han logrado desarrollar tomates transgénicos con un retraso considerable en la podredumbre del fruto, durante la maduración del mismo (flavor savor); también se produce un triturado de tomate más viscoso muy adecuado para la producción de zumos, pasta o ketchup.

Otro problema organoléptico común es el pardeamiento de los vegetales. La base bioquímica de este problema es la síntesis de la enzima polifenoloxidasa, que produce polifenoles de naturaleza melaniforme. Se han conseguido patatas transgénicas que tienen inhibida la síntesis del gen de la polifenoloxidasa, logrando tubérculos que tardan horas en pardear.

Para su uso en India, principalmente, se ha producido una berenjena transgénica, debido a que este país es el segundo exportador de la misma y es parte de su dieta básica. El gran problema es que la berenjena es muy afectada por diferentes insectos y enfermedades que causan pérdidas importantes que pueden alcanzar hasta el $60 \%$ ○ $70 \%$ de los cultivos, por lo que estos necesitan gran cantidad de insecticidas. Se espera que la producción de la berenjena Bt reduzca en un $80 \%$ las aplicaciones de insecticidas para controlar los barrenadores del fruto y del brote (James, 2009).

Otro hecho notorio es la producción de manzanas que producen proteína anticaries como parte de su propio desarrollo. Esta proteína se aisló y se insertó el gen que produce la proteína p 1025 que ocupa los espacios en la dentadura e impide que se establezca la bacteria de la caries.

Además, destaca la producción de una papa a la que se le incorporaron los genes de una enzima que aumenta la ruptura de la glucosa y la producción de almidón. Esto permite la producción de papas ricas en glucosa y en almidón para ser utilizadas en la industria de alimentos procesados (Garro \& Lam, 2009).

Recientemente se logró producir el maíz SmartStax ${ }^{\mathrm{TM}}$, que es el resultado de un acuerdo de licencia recíproca y colaboración en investigación y desarrollo firmado en 2007 entre Monsanto y Dow AgroSciences.

El SmartStax ${ }^{\mathrm{TM}}$ es un producto multievento basado en un total de ocho genes. Este es el cultivo biotecnológico de eventos apilados más avanzado que se ha autorizado hasta la fecha y está diseñado para proporcionar el máximo control de plagas de insectos en el maíz (tanto de superficie como subterráneos), además de tolerancia a herbicidas para el control de malezas. SmartStax ${ }^{\mathrm{TM}}$ es una pila cuádruple de productos aprobados de los siguientes eventos: MON 89034 × TCI507 × MON 88017 × DAS-59I22-7 (James, 2009):

I) MON 89034 expresa las proteínas CryzAb y CrylA.I05 que son complementarias para el control de las plagas de lepidópteros.

2) TCI507 expresa la proteína CrylF de control de lepidópteros y la proteína BAR de tolerancia al glufosinato.

3) $\mathrm{MON} 88017$ expresa la proteína Cry3BbI de control del gusano de la raíz del maíz (Diabrotica virgifera) y la proteína CP4 de tolerancia al glifosato.

4) DAS-59/22-7 expresa una proteína binaria Cry34/35AbI de control del gusano de la raíz del maíz (Diabrotica virgifera) y la proteína BAR de tolerancia al glufosinato. 
En total, hay ocho genes (cry2Ab, cryl A. I05, crylF, cry3Bb I, cry34, cry35Ab I, cp4 y bar) que codifican los tres eventos siguientes: control de insectos de superficie, control de insectos subterráneos y tolerancia a herbicidas.

Entre las múltiples características que poseen las plantas transgénicas, la más utilizada ha sido la tolerancia a herbicidas, ya que representó, para el 2009, un $62 \%$ de las hectáreas cultivadas con soja, maíz, canola, algodón, betabel y alfalfa, que provocó un aumento de poco más del 5\% en comparación con lo obtenido en 2008 (James, 2009).

\section{Perspectivas de desarrollo (20 I 0-20 I 5)}

En muchos países, la percepción pública de estos alimentos no sido muy favorable, lo cual ha obedecido, entre otras, a dos razones principales:

El temor de muchos sectores productivos tradicionales, para los cuales los cultivos y alimentos transgénicos representan una amenaza comercial dados los bajos costos de producción que han generado a nivel mundial. Un problema socioeconómico y no tecnológico.

Ligado a este temor, muchos grupos ambientalistas han generado movimientos antitransgénicos en los cuales la población y el consumidor común se han visto bombardeados de información poco seria que, en la mayoría de los casos, pretende sembrar dudas y mitos sobre la seguridad de esta tecnología. Un problema de educación.

Como indican Aboites y Félix (20 I I), la percepción pública negativa, también visualizada como falta de conciencia pública respecto a sus beneficios, es el renglón que comparten todos los países como la principal limitante para el desarrollo de la biotecnología, seguido del correspondiente a infraestructura/ debilidad institucional/capacidad técnico-científica. Esto muestra un escenario en el que, junto con insuficiencias y carencias materiales, la sociedad advierte que pueden interpretarse como temores acentuados al riesgo (Aboites \& Félix, 20I I).

A nivel mundial se tiene claro que la percepción pública se relaciona directamente con el grado de educación; a mayor nivel de educación, mayor aceptación de los alimentos transgénicos. De esta forma se puede esperar que la opinión de los consumidores cambie drásticamente cuando puedan medir de forma cualitativa la diferencia entre un alimento convencional y otro generado por técnicas de la biotecnología moderna.

Aunque los transgénicos han traído consigo mucha controversia en los grupos ambientalistas y otras organizaciones en contra, para otras personas resulta una excelente forma de dar esperanza en el mundo para la producción de más y mejores alimentos que podrán contribuir, junto con los alimentos convencionales, a paliar el hambre mundial, la cual, de acuerdo con la FAO, alcanzó a mil millones de personas para el 2009. Y esta ha seguido aumentando debido a que, como la población mundial crece, el área per cápita para la siembra se reduce cada vez más.

Por todo ello, se espera que la agrobiotecnología se presente como una respuesta a largo plazo, y no de corto plazo de solo brindar alimentos, y de esta forma garantizar mejoras en los rendimientos y un uso sostenible de los recursos, dándoles oportunidad a los pequeños agricultores de trabajar eficientemente.

Junto a los cultivos, los productores agrobiotecnológicos están en continuo aumento, por ejemplo, para el 2009 se registraron en India 600000 pequeños agricultores más, siendo este el mayor incremento de productores (James, 2009).

Se espera que los cultivos biotecnológicos contribuyan al cumplimiento exitoso del Objetivo de Desarrollo del Milenio (ODM) de reducir la pobreza a la mitad en el horizonte del 20I5. La mayor renta que están generando los cultivos biotecnológicos en países como India y China para los pequeños agricultores pobres supone una modesta contribución inicial para mejorar su condición.

Además, en los próximos años se espera que se dé aún más un auge de los alimentos modificados para beneficio directo de los consumidores, que podrán medir las nuevas cualidades de los alimentos mejorados, tales como la presencia de proteínas extrañas a su naturaleza y medicamentos o compuestos que favorezcan las dietas de las personas.

\section{Impacto económico de la siembra de CGM en el mundo}

Aunque la crisis económica afectó fuertemente todos los sectores del mercado en los últimos años, 
no se alcanzaron mayores porcentajes de aumento que en años anteriores, sin embargo, en todos los cultivos transgénicos se alcanzaron números nunca antes vistos (figural).

El total mundial de área sembrada con cultivos transgénicos alcanzó en 2010 los 148 millones de hectáreas, lo cual se traduce en un incremento del I0\% comparado con el dato del 2009, que fue de 134 millones de hectáreas (James, 2010). Por ejemplo, en el caso de la soja, se logró que más de las tres cuartas partes del cultivo mundial fuera de soja transgénica y no convencional y que el algodón alcanzara casi la mitad, con un 49\%. Y no solo aumentó la cantidad de hectáreas sembradas, sino también el número de agricultores de todo el mundo que decidieron producir cultivos biotecnológicos.

Principalmente se mencionan los 29 países en los que se sembró mayor cantidad de cultivos transgénicos, y cabe recalcar que en estos 29 países habita más de la mitad del mundo, es decir, un 59\% para un total de 4.000 millones de personas; y más de la mitad de los 1.500 millones de hectáreas de cultivo del mundo se encuentran en esos 29 países, siendo los 148 millones de hectáreas de cultivos biotecnológicos el 10\% de las hectáreas del mundo (James, 2010).

Este aumento de los últimos años se debe a los países que fueron pioneros en la tecnología de los cultivos biotecnológicos. Y lo anterior tiene que ver con la aplicación de eventos apilados en lugar de los simples o de una sola variedad o híbrido, alcanzando niveles óptimos en los principales cultivos, como maíz y algodón, en los grandes países agrobiotecnológicos.

Estos eventos satisfacen las múltiples necesidades de los agricultores y consumidores, y encuentran cada vez mayor aplicación en II países: por número de hectárea de mayor a menor número: Estados Unidos, Argentina, Canadá, Filipinas, Sudáfrica, Australia, México, Chile, Colombia, Honduras y Costa Rica (James, 2009).

Por ejemplo, en 2009, un impresionante $85 \%$ de los 35,2 millones de hectáreas de cultivo de maíz en Estados Unidos eran biotecnológicas y hay que destacar que el $75 \%$ de ellas estaban ocupadas por híbridos de dos o tres eventos apilados, mientras que solo el $25 \%$ se destinaban a híbridos de un solo evento.

Con este y otros ejemplos, como el gran papel que ha jugado Filipinas, es claro que los eventos apilados se han convertido en una parte muy importante de los cultivos biotecnológicos; además, este gran incremento a 148 millones de hectáreas no tiene precedentes en la historia y convierte los cultivos biotecnológicos en la tecnología agrícola que más rápidamente se ha adoptado en la historia (James, 2009).

Además del aumento de hectáreas sembradas, hubo un aumento directamente relacionado al de

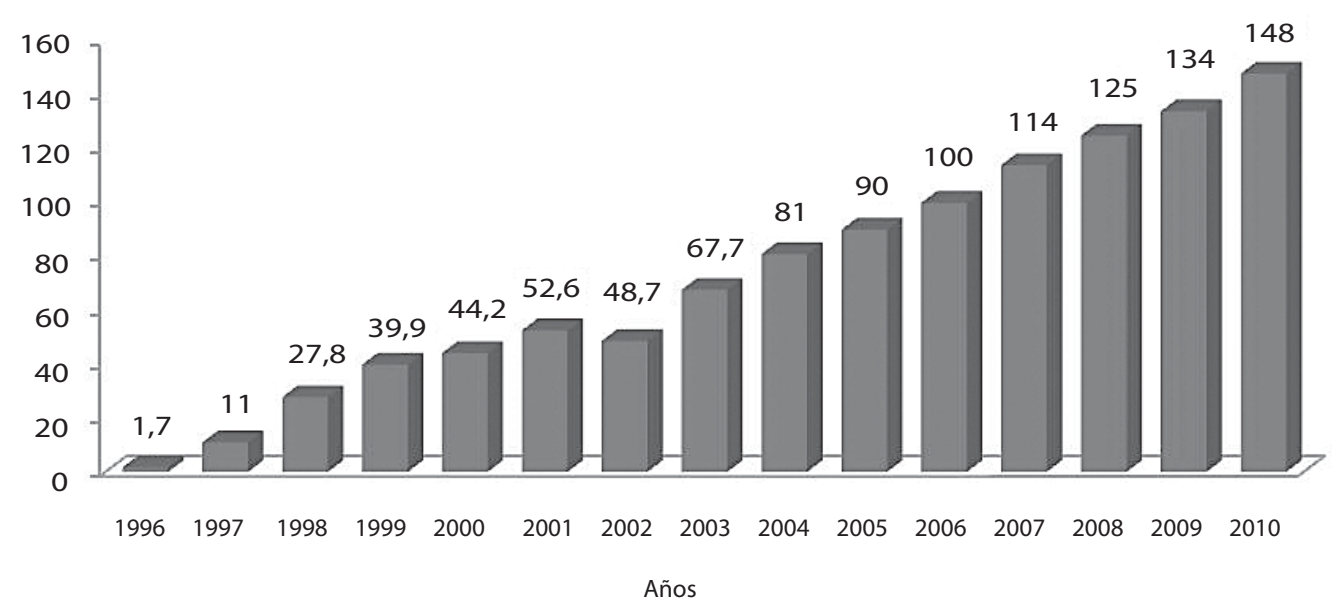

Figura I. Evolución en el tamaño del área sembrada de cultivos OGM a nivel mundial en el periodo de 1996-2010, según James (2010). 
los cultivos, el de los agricultores beneficiarios de los cultivos biotecnológicos. Para el 2009 se alcanzó la cifra de 14 millones en 25 países, lo que supone un incremento de 700000 con respecto al 2008, en que habían 13,3 millones.

De los 14 millones del 2009, más del 90\% eran pequeños agricultores pobres (la mayoría productores de algodón Bt) provenientes de China, India (algodón Bt), Filipinas (maíz biotecnológico) y aproximadamente el millón restante de países industrializados como Estados Unidos y Canadá o de países en desarrollo como Argentina y Brasil. En China, los primeros estudios indican que otros 10 millones de pequeños agricultores pobres de ese país podrían ser beneficiarios secundarios del algodón Bt (James, 2009).

Los países en desarrollo acaparan cada vez más la producción agrobiotecnológica mundial, alcanzando ya casi la mitad con un 48\% frente al 44\% del 2009 de las 134 millones de hectáreas sembradas, lo que equivale a 61,5 millones de hectáreas, y cabe prever que continúen registrando incrementos significativos en el futuro.

Los cinco grandes países en desarrollo cuya población colectiva asciende a 2.800 millones de habitantes en los tres continentes del Sur siguieron ejerciendo un fuerte liderazgo global, con la plantación de unos 57 millones de hectáreas, equivalentes al $43 \%$ de la superficie agrobiotecnológica global, con 21,4 millones en Brasil, 21,3 millones en Argentina, 8,4 millones en India, 3,7 millones en China y 2,I millones en Sudáfrica.

En conjunto, representan a 1.300 millones de personas que dependen por completo de la agricultura, con millones de pequeños agricultores pobres y campesinos sin tierra, que conforman la gran mayoría de los pobres del mundo. Las inversiones que realizan estos países en investigación y desarrollo agrobiotecnológicos son de gran cuantía, situándose incluso en el nivel de las grandes compañías multinacionales.

Cabe destacar que, de los US\$5I 900 millones de beneficios adicionales generados por los cultivos biotecnológicos para la renta de los agricultores durante los 13 primeros años de comercialización (1996-2008), la mitad (US\$26 100 millones) se generaron en países en desarrollo y la otra mitad
(US\$25 800 millones) en países industrializados (Brookes \& Barfoot, en preparación).

Entre 1996 y 2008 se lograron obtener US\$5 I 900 millones de beneficio económico, el 49,6\% de lo cual fue generado por los incrementos de rendimiento y el $50,4 \%$ por la reducción de los costos de producción.

En 2008, el incremento total de la producción de los cuatro cultivos biotecnológicos principales (soja, maíz, algodón y colza o canola) fue de 29,6 millones de toneladas métricas, que hubieran requerido 10,5 millones de hectáreas adicionales si no se hubieran utilizado cultivos biotecnológicos.

La biotecnología ya ha contribuido a aumentar la productividad y reducir los costos de producción de los cultivos biotecnológicos actuales y encierra un enorme potencial para el futuro cuando se aplique a cultivos esenciales como el arroz y el trigo, así como a cultivos de subsistencia para los pobres, como la yuca.

Según Brookes y Barfoot (en preparación) para 2008 se logró alcanzar un total de US\$9 200 millones (US\$4 700 millones en países en desarrollo y US\$4 500 millones en países industrializados).

Los beneficios acumulados durante el periodo $1996-$ 2008 ascienden a US\$5I 900 millones (US\$26 100 millones en países en desarrollo y US\$25800 millones en países industrializados). Y estas estimaciones incluyen los importantísimos beneficios asociados al doble cultivo de soja biotecnológica en Argentina.

Para 20 I0, el número de países agrobiotecnológicos se mantuvo en 29, tras la incorporación de Costa Rica en 2009, y el abandono del maíz Bt por parte de Alemania al finalizar la temporada 2008. En Costa Rica solo se producen cultivos biotecnológicos exclusivamente con destino al mercado de exportación de semillas, al igual que sucede en Chile. Sin embargo, gracias a que Costa Rica se unió a los países que más producen en el mundo, se alcanzó la cifra histórica de 10 países agrobiotecnológicos en América Latina (James, 20l0).

En las estadísticas del 2010, los cultivos con mayor área sembrada no han variado en gran cantidad. Los principales cultivos transgénicos siguen siendo la soja, el algodón, el maíz y la colza o canola.

Entre estos cuatro, el de mayor área global sigue siendo la soja, de la cual se han sembrado 73,3 millo- 
nes de hectáreas, lo que equivale al 50\% del total de estos cuatro cultivos. En el caso del algodón fueron 21 millones de hectáreas para un 14\%, para el maíz un $31 \%$ para un total de 46,8 millones de hectáreas y para la canola, 7 millones de hectáreas para un total del 5\% (figura 2) (James, 20l0).

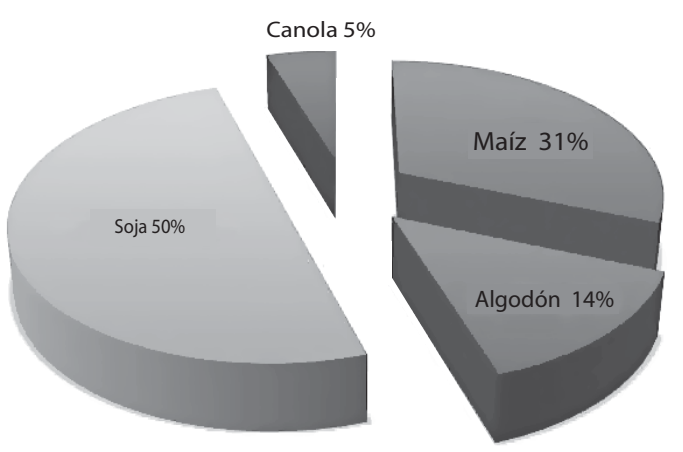

Figura 2. Principales cultivos a nivel mundial y su proporción del total de área cultivada con transgénicos, según James (20l0).

\section{Aporte de Latinoamérica en el mercado mundial de cultivos biotecnológicos}

En Latinoamérica, la experiencia del cultivo de variedades mejoradas portécnicas de la biotecnología moderna se ha ido incrementando y está produciendo impactos importantes en la actividad agrícola, sobre todo generando experiencia de manejo (en algunos casos controlado) y reactivando economías por el aprovechamiento de tierras en abandono y la oferta de empleo en regiones socialmente deprimidas.

Sin embargo, a pesar de que esta podría ser una buena opción para el desarrollo y reactivación de la agricultura en regiones pobres, quizá una estrategia interesante de evaluar a partir de la experiencia generada hasta la fecha sería la inserción estratégica de cultivos alimentarios que incluyan tratamientos novedosos, como las mejoras en contenido (proteínas, vitaminas y aminoácidos), que se encuentran en fases finales de investigación y se espera estén en el mercado en pocos años.

Este tipo de alimentos tendrán un valor agregado muy alto e incidirán notablemente en la percepción pública, pues los consumidores tendrán mayores opciones para mejorar su calidad de vida por el consumo de alimentos funcionales.

Los grandes productores latinoamericanos de cultivos transgénicos han sido Argentina, Brasil y México. Los dos primeros, ubicándose entre los cuatro megaproductores a nivel mundial con 17,1 y 9,4 millones de hectáreas sembradas, respectivamente. A partir del 2002 se nota la inserción de países como Uruguay y Paraguay con una producción (soja y maíz) nada despreciable, y I,8 y 0.3 millones de hectáreas sembradas respectivamente. Por otro lado, Honduras ha mostrado un comportamiento creciente de producción desde su inicio en 2002, cuando sembró 500 hectáreas de maíz alcanzando las 2000 en el 2003. Por su parte, Colombia alcanzó las 5.000 hectáreas en 2003 (James, 2004).

Queda claro que estos países latinoamericanos han hecho una apuesta por la biotecnología. En la mayor parte de los casos esta ha sido una decisión de país, lo cual ha permitido articular desde la base gubernamental diversos sectores para que tomen un papel de actores en el desarrollo científico nacional. Los que han iniciado este proceso con anterioridad están actualmente dando los frutos de esas decisiones.

Un ejemplo de ello es la inversión en investigación y desarrollo de biocombustibles hecha por Brasil hace más de 30 años, a partir de la cual hoy se posiciona como uno de los países líderes a nivel mundial en el uso de esta tecnología. Y no solo en esta área, pues Brasil ha hecho aportes muy significativos en temas de biotecnología vegetal y médica.

Recientemente, una asociación entre la Empresa Brasileña de Pesquisa Agropecuaria (EMBRAPA), la Universidad de Brasilia, la Escuela Paulista de Medicina y la Universidad Federal de Sao Paulo busca desarrollar plantas (soja) y animales transgénicos (vacas) capaces de producir el "factor IX", proteína responsable de la coagulación de la sangre y de la que carecen los hemofílicos.

La investigación se desarrolla en los laboratorios de EMBRAPA, Recursos Genéticos y Biotecnología, en Brasilia, una de las 40 unidades de la empresa, bajo la coordinación del investigador Elíbio Rech (Alfa Editores, 2005).

Otros eventos de igual o mayor importancia para la industria médica y la salud se están desarrollando en países de la región como Argentina, Chile y 
Colombia, donde la biotecnología ha sido impulsada de forma decidida por diversas instituciones tanto privadas como gubernamentales.

En Centroamérica, la biotecnología existente se enfoca principalmente al cultivo de tejidos y en cada país se han detectado instituciones que trabajan con marcadores moleculares, ya sea como herramienta auxiliar en el mejoramiento asistido o como herramienta que se orienta al proceso de multiplicación de plantas libres de patógenos (Aboites \& Félix, 20 II). Según Aboites y Félix (20 I I), en todos los países hay evidencia de conservación in vitro e incluso de críoconservación, aunque actividades de ingeniería genética a nivel de laboratorio y como parte de programas académicos solo se identificaron en Guatemala (papaya), Honduras (frijol) y Costa Rica, único país que muestra evidencia de cubrir la gama completa de biotecnologías.

\section{La experiencia de Costa Rica en biotecnología}

En Costa Rica se reproducen semillas transgénicas para uso exclusivo de exportación. Tal es el caso del algodón (cerca de 1.000 hectáreas), soya (menos de 20 hectáreas) y en el pasado se reprodujo semilla de maíz. Asimismo, en Costa Rica el desarrollo de actividades en biotecnología ha estado en manos de las universidades públicas.

Por otro lado, se llevan a cabo pruebas de campo (menos de 20 hectáreas) para cultivos de piña modificados con incremento de $\beta$-caroteno. Un estudio reciente encontró 195 proyectos de investigación en biotecnología en este país (Valdez et al. 2004). En este mismo estudio se ubicaron las categorías con mayor importancia, en las cuales los proyectos corresponden a Bio-Agro (39\%), Bio-Salud Humana (30\%) y procesamiento de alimentos (7\%).

Existen proyectos de investigación con plátano, banano y arroz (proyecto modelo UCR) que procuran resolver importantes problemas de estos cultivos y que en caso de que en un futuro sean desregulados (permitido su uso comercial), tendrían importantes beneficios tanto desde el punto de vista agronómico como económico, social y ambiental, dado que al lograrse una resistencia genética a diferentes plagas, se estaría reduciendo significativamente la utilización de plaguicidas químicos.
Por otro lado, junto a la labor en investigación también se han generado algunos esfuerzos en la difusión y formación de recurso humano en diversas áreas de la biotecnología por parte de las universidades públicas. La Escuela de Biología del Instituto Tecnológico de Costa Rica abrió en 1997 la carrera de Ingeniería en Biotecnología. Esta carrera a la fecha ha graduado 362 profesionales, los cuales están teniendo gran éxito en su inserción laboral, tanto en la empresa privada como en las instituciones públicas y con seguridad su aporte al desarrollo de la biotecnología en Costa Rica será de gran valor.

A nivel centroamericano, Costa Rica se encuentra en primer lugar en cuanto a la formación de profesionales en el área, con 64\% y 68\% de los doctorados y maestros en ciencias que trabajan en biotecnología, seguido por Honduras, Nicaragua, Guatemala, Panamá y, finalmente, El Salvador, según datos de Aboites y Félix (20 I I). En cuanto a infraestructura, una vez más, Costa Rica posee 33\% de los institutos de investigación y más de la mitad de los institutos privados de la zona, seguido por Nicaragua, Guatemala, Honduras, Panamá y El Salvador.

Por otra parte, Aboites y Félix (20I I) establecen que Costa Rica es el único país centroamericano que posee una política que promueve la vinculación entre el aspecto científico y tecnológico con el área productiva de manera sistemática y como parte de una política estatal, además, indican que es el único país donde se documentan vínculos entre biotecnologías de tercera generación con el sector productivo, por ejemplo, en el Centro Nacional de Innovaciones Biotecnológicas (CENIBiot) (Aboites \& Félix, 20|l).

De acuerdo con Trigo y Villarreal (2009), las políticas en bioseguridad se clasifican en tres tipos y puede decirse que Centroamérica, y propiamente en Costa Rica, se ubica más en torno a una política preventiva que a una promocional o neutra (cuadro 3).

Con respecto a las políticas de bioseguridad en Costa Rica en cuanto a la producción de cultivos y alimentos, no se ha permitido la comercialización de ningún organismo transgénico de uso en la agricultura. En el país existen políticas preventivas (cuadro 4) para estos organismos en la Ley de Protección Fitosanitaria ( $N^{\circ}$ 7664) y todo proyecto de investigación o de reproducción de semillas es previamente revisado por la Comisión Técnica Nacional de Bioseguridad, que realiza la evaluación de riesgos 
Cuadro 3. Centroamérica: Políticas de bioseguridad para cultivos transgénicos, 2009.

\begin{tabular}{|c|c|c|c|}
\hline País & Políticas promocionales & Políticas neutras & Políticas preventivas \\
\hline & $\begin{array}{l}\text { Evaluaciones basadas } \\
\text { exclusivamente en información } \\
\text { generada en aprobaciones } \\
\text { realizadas en otros países. Análisis } \\
\text { de riesgo no asume ningún tipo } \\
\text { de percepción a priori. }\end{array}$ & $\begin{array}{l}\text { Evaluaciones caso por caso con } \\
\text { base en riesgos demostrados } \\
\text { o incertidumbres científicas y } \\
\text { riesgos esperados vinculados } \\
\text { a la novedad del proceso de } \\
\text { transformación. }\end{array}$ & $\begin{array}{l}\text { Evaluaciones caso por caso con } \\
\text { base en riesgos demostrados o } \\
\text { incertidumbres científicas y riesgos } \\
\text { esperados vinculados a la novedad } \\
\text { del proceso de transformación. }\end{array}$ \\
\hline $\begin{array}{l}\text { Guatemala } \\
\text { El Salvador } \\
\text { Honduras } \\
\text { Nicaragua } \\
\text { Costa Rica } \\
\text { Panamá }\end{array}$ & & $\sqrt{\sqrt{ }}$ & $\begin{array}{l} \pm \sqrt{ } \\
\pm \sqrt{ } \\
\pm \sqrt{ } \\
\pm \sqrt{ }\end{array}$ \\
\hline
\end{tabular}

Nota: $\pm \sqrt{ }$ Aunque no se ha definido una política en bioseguridad, esto parece una estrategia tipo política preventiva. Fuente:Trigo y Villarreal, 2009.

\section{Cuadro 4. Marco legal relacionado con biotecnología, 2005.}

\begin{tabular}{|c|c|c|c|c|c|c|c|}
\hline Aspecto & Guatemala & El Salvador & Honduras & Nicaragua & Costa Rica & Panamá & Total \\
\hline $\begin{array}{l}\text { Bioseguridad } \\
\text { (Instrumentos } \\
\text { específicos) }\end{array}$ & $\begin{array}{l}\text { Acuerdos } \\
\text { ministeriales } \\
\text { MAGA 393- } \\
98 \text { y } 476-98\end{array}$ & & $\begin{array}{l}\text { Proyecto } \\
\text { de ley en } \\
\text { proceso } \\
\text { final de } \\
\text { elaboración } \\
\text { SERNA }\end{array}$ & $\begin{array}{l}\text { Proyecto de } \\
\text { Ley sometido } \\
\text { Asamblea } \\
\text { Nacional }\end{array}$ & $\begin{array}{l}\text { Reglamento } \\
\text { auditorías en } \\
\text { Bioseguridad } \\
\text { Agrícola } \\
\text { Decreto } \\
\text { MAG 32486- } \\
2005\end{array}$ & $\begin{array}{l}\text { 48-2002 } \\
\text { Comisión NL } \\
\text { Bioseguridad } \\
\text { Res. ANAM } \\
502 \text { Marco } \\
\text { Bioseguridad }\end{array}$ & -1 \\
\hline $\begin{array}{l}\text { Protocolo } \\
\text { Cartagena }\end{array}$ & Ratificado & Ratificado & $\begin{array}{l}\text { No ha sido } \\
\text { ratificado }\end{array}$ & Ratificado & $\begin{array}{l}\text { No ha sido } \\
\text { ratificado }\end{array}$ & Ratificado & -1 \\
\hline Biodiversidad & $\begin{array}{l}\text { Dls. 4-89; } \\
\text { 5-95; 101-96; } \\
\text { 68-72; 68-86 } \\
\text { Ams. I77-95; } \\
\text { 722-01 }\end{array}$ & $\begin{array}{l}\text { Dls. 844- } \\
94 ; \\
\text { 579-05; } \\
\text { 233-98 }\end{array}$ & & $\begin{array}{l}\text { Proyecto de } \\
\text { ley } b\end{array}$ & $\begin{array}{l}\text { Leyes } 7317- \\
92 \text { Ley } \\
7788-98\end{array}$ & Ley No 2-95 & -1 \\
\hline Semillas & $x$ & & & & $x$ & & -1 \\
\hline $\begin{array}{l}\text { Comisión en } \\
\text { Biotecnología }\end{array}$ & I & I & I & & I & I & \\
\hline $\begin{array}{l}\text { Comisión en } \\
\text { Bioseguridad }\end{array}$ & I & I & I & I & I & I & \\
\hline
\end{tabular}

Fuente: Aboites y Félix, 2011.

y emite las recomendaciones pertinentes para la ejecución de cada experiencia bajo condiciones de seguridad que permitan prevenir los posibles riesgos derivados de la introducción de cualquier organismo transgénico en el ambiente nacional.

La Comisión Técnica Nacional de Bioseguridad (CTNBio) fue creada hace 13 años (Decreto $N^{\circ}$
2692 I del 20 marzo de 1998) y está integrada por representantes de las instituciones públicas, como la Gerencia de Biotecnología del MAG, la Oficina Nacional de Semillas, el MICIT, el Ministerio de Salud Pública y representantes de la Academia de Ciencias.

Recientemente se modificó la constitución de la comisión para incluir a representantes de la 
Federación para la Conservación del Ambiente y la Red de Coordinación en Bioseguridad (Decreto $N^{\circ}$ 31946 del 4 de octubre del 2004). La Comisión ha participado de forma activa en congresos y reuniones internacionales sobre bioseguridad en instancias como la FDA, la USDA y el Codex Alimentarius, órgano internacional de referencia en aspectos de bioseguridad alimentaria y etiquetado de alimentos.

Además, con el apoyo de instituciones académicas y otras instituciones públicas, la CTNBio ha generado diversas instancias de difusión y debate de aspectos de la biotecnología moderna.

En la actualidad, la CTNBio ha recibido apoyo internacional del Programa de las Naciones Unidas para el Medio Ambiente (PNUMA) y el Fondo para el Medio Ambiente Mundial (UNEP-GEF, siglas en inglés) para la implementación del Protocolo de Cartagena sobre Bioseguridad de la Biotecnología moderna, derivado de la Convención sobre la Biodiversidad; en este proyecto se trabaja sobre todo en el fortalecimiento de la infraestructura de las autoridades competentes en la gestión de la implementación del Protocolo de Cartagena.

De forma paralela se desarrolla un proyecto titulado Construcción de capacidades multipaís para el cumplimiento del protocolo de Cartagena (Lac-Biosafety) financiado por UNEP-GEF, en el cual varios países latinoamericanos (Brasil, Colombia, Perú) junto con Costa Rica están generando diversas experiencias de investigación que servirán como insumos importantes para los tomadores de decisión en la aprobación de solicitudes de siembra de OGM en los países participantes.

De esta forma, la sociedad civil ha tenido una diversidad de espacios en foros, talleres y cursos en los cuales expresar sus opiniones e inquietudes con relación a las ventajas y posibles efectos adversos en la adopción de estas tecnologías. En la actualidad se encuentra en curso un proyecto nacional que procura ampliar la regulación a otras áreas de aplicación biotecnológica: ambiente, salud pública, actividad pecuaria.

En el marco nacional de bioseguridad y la investigación científica en aspectos de biotecnología moderna, tales como los cultivos y alimentos transgénicos, se han generado experiencias muy positivas que permiten ir consolidando e integrando ideas y procedimientos importantes que fortalecerán el desarrollo científico del país.
Esta panorámica nacional, junto con la experiencia de los demás países de la región latinoamericana, podría suponer un desarrollo acertado de la biotecnología agrícola y alimentaria.

Diversas instituciones han fijado como meta el fortalecimiento de programas en biotecnología, lo cual debe ser una meta común de los gobiernos locales con el fin de tener visiones integrales y articuladas que permitan desarrollar estrategias de país y no simples esfuerzos individualizados que a la postre resulten frustrados o sean sometidos a un tortuoso camino antes de ser aceptados y validados por la población civil.

\section{Bibliografía}

ArgenBio (2007). Cultivos tolerantes a herbicidas (TH). Consultado en Sept. 20II. Obtenido desde: http:// www.argenbio.org/h/biotecnologia/ / 2.php

ArgenBio (2007). Alergias alimentarias. El Cuaderno de Por qué Biotecnología. Edición $N^{\circ} 8$.

ArgenBio (20 I I). Cultivos transgénicos, lo que hay y lo que vendrá. El Cuaderno de Por qué Biotecnología. Edición $\mathrm{N}^{\circ} 130$.

Aboites, G. \& Félix, G. (20II). Centroamérica: Uso de semillas Genéticamente Modificadas e Incremento del Ingreso de los Agricultores. México, D. F.: Comisión Económica para América Latina y el Caribe (CEPAL).

Alfa Editores (2005). Empresa brasileña producirá proteína contra la hemofilia mediante soya y vacas transgénicas. Obtenido desde: www.alfa-editores.com.

Bayer CropScience (20 I I). BioScience, Soluciones integrales y más. Consultado en Sept. 201 I. Obtenido desde:

http://www.bayercropscience.com.uy/institucional. php?contentID $=16$

Bioplanet (200 I). Plantas modificadas: Y de postre... una vacuna. Consultado en Sept. del 2011. Obtenido desde:

http://www.bioplanet.net/magazine/bio_mayjun_200 I_ mayjun_industria.htm

Brookes, G.y Barfoot, P.En preparación. Cultivos Transgénicos: El Impacto Global Socio-económico y Ambiental de los Años 1996-2009. Economics.

Brown, K. (1997). La elaboración de vacunas de bajo costo para uso masivo. Noticias de Seguridad (I2): 31-34.

Garro G. (2004). Biotecnología moderna e inocuidad alimentaria. Alimentaria 75: 34-37. Septiembre-Octubre. 
Garro, G. \& Lam, K.M. (2009). Aplicación de la biotecnología moderna en la producción de alimentos de mayor valor nutricional. Alimentaria ( I0 I): 29-33.

Garro, G. (2010). Ingeniería Genética de Plantas: Aspectos generales, aplicaciones y prácticas de laboratorio. Material de Apoyo. Cartago: Instituto Tecnológico de Costa Rica. Pp. 76.

ICA (2004). Evaluación de los riesgos potenciales para introducir y comercializar semillas de algodón con las tecnologías conjuntas (Bollgard) + (Rounduo Ready). Documento de Trabajo. Bogotá: Instituto Colombiano Agropecuario. II p.

James, C. (2004). Global Status of Commercialized Biotech/ GM Crops: 2004. ISAAA Briefs No. 32. Ithaca, NY: ISAAA

James, C. (2009). Global Status of Commercialized Biotech/ GM Crops: 2009. ISAAA Brief No. 4I. Ithaca, NY: ISAAA.

James, C. (2010). Global Status of Commercialized Biotech/ GM Crops: 2010. ISAAA Brief No. 42. Ithaca, NY: ISAAA.

Konig,A.; Cockburn A.; Crevel, R.; Debruyne, E.; Grafstroem, R.; Hammerling, U.; Kimberg, l.; Knudsen, I.; Kuiper, H.; Peijnenburg, A.; Penninks, A.; Poulsen, M.; Schauzu, M.
\& Wal, J.M. (2004). Assesment of the safety of foods derived from genetically modified (GM) crops. Food and Chemical Toxicology 42: 1047- 1088.

Ma, J.; Drake, P. \& Christou, P. (2003). The production of recombinant pharmaceutical proteins in plants. Nature Reviews-Genetics, Vol. 4.

Ocando, O. (2005). Algodón Genéticamente Modificado. I ed. Bogotá: AGROBIO.

Pantanelli, A. (2007). Alimentos fortificados y enriquecidos. Revista Alimentos Argentinos 14: I-5.

Traxler, G.; Godoy-Avila, S.; Falck-Zepeda, J. \& EspinozaArellano,J.(2003). Transgenic Cotton in Mexico:Economic and Environmental Impacts. En: Kalaitzandonakes, N. (ed.). Economic and Environmental Impacts of First Generation Biotechnologies. New York: Kluwer Academic.

Trigo, E \& Villarreal, F. (2009). La agrobiotecnología en las Américas: una mirada a la situación actual y a las tendencias futuras. San José: IICA (ISBN 13: 978-929248-030-1).

Valdez, M.; López, R. \& Jiménez, L. (2004). Estado actual de la biotecnología en Costa Rica. Rev. Biol.Trop. 52(3): 733-743. 